\title{
Narrative review: association between lung cancer development and ambient particulate matter in never-smokers
}

\author{
Jeong Uk Lim, Hyoung Kyu Yoon \\ Division of Pulmonary, Allergy and Critical Care Medicine, Department of Internal Medicine, Yeouido St. Mary's Hospital, College of Medicine, \\ The Catholic University of Korea, Seoul, Republic of Korea \\ Contributions: (I) Conception and design: Both authors; (II) Administrative support: Both authors; (III) Provision of study materials or patients: \\ Both authors; (IV) Collection and assembly of data: Both authors; (V) Data analysis and interpretation: Both authors; (VI) Manuscript writing: Both \\ authors; (VII) Final approval of manuscript: Both authors. \\ Correspondence to: Dr. Hyoung Kyu Yoon. Division of Pulmonology and Critical Care Medicine, Department of Internal Medicine, Yeouido St. Mary's \\ Hospital, School of Medicine, The Catholic University of Korea, Seoul 150-713, Republic of Korea. Email: cmcyhg@catholic.ac.kr.
}

Objective: To review the association and pathophysiological link between lung cancer in never smokers and ambient particulate matter (PM).

Background: Although the association between exposure to PM and lung cancer development is well known, the pathophysiological background is yet to be studied in depth. Never smokers comprise a large proportion of newly diagnosed lung cancer cases and account for $25 \%$ of all cases. Considering the carcinogenic nature of ambient PM and the fact that many patients with lung cancer are never smokers, it is necessary to evaluate the interrelation and possible clinical background, in order to effectively prevent lung cancer development in this subgroup.

Methods: An online search of literature was conducted. The National Center for Biotechnology Information (NCBI), PubMed, Google Scholar, Cochrane Library and EMBASE were searched.

Conclusions: In never smokers, the risk of lung cancer was dose-dependent with the concentration of ambient air pollutants. Regarding the pathophysiological link, involvement of epithelial mesenchymal transition (EMT) and chronic inflammation has been mentioned, but further studies are necessary to enable therapeutic interventions to prevent cancer development. Considering the significant burden of PM on lung cancer development, both public and clinical approaches to cancer prevention are essential. To prevent lung cancer more effectively, clinicians should develop a more individualized approach in patients, focusing on gender and genetic background.

Keywords: Particulate matter (PM); lung cancer; never smoker; pathophysiology; carcinogenesis

Submitted Apr 14, 2021. Accepted for publication Jan 11, 2022.

doi: $10.21037 /$ jtd-21-655

View this article at: https://dx.doi.org/10.21037/jtd-21-655

\section{Background}

Lung cancer is one of the leading causes of cancer-related deaths worldwide (1). Tobacco smoking is a well-known cause of lung cancer (2). Nevertheless, never smokers comprise a large proportion of newly diagnosed lung cancer cases and account for $25 \%$ of all cases (3). Recently, the proportion of never smokers among newly diagnosed lung cancer cases has been increasing steadily (4-7); in some countries, a considerable proportion of lung cancer seen among women were in never smokers (8-10). There are other factors associated with lung cancer development, such as exposure to secondhand smoke, radon, household fumes, occupational exposure to carcinogens, and infections $(11,12)$. Above all, the World Health Organization (WHO) has classified air pollution as carcinogenic to humans (International Agency for Research on Cancer, Group 1), and many countries have monitoring systems to measure levels of ambient pollutants, such as respirable particulate 


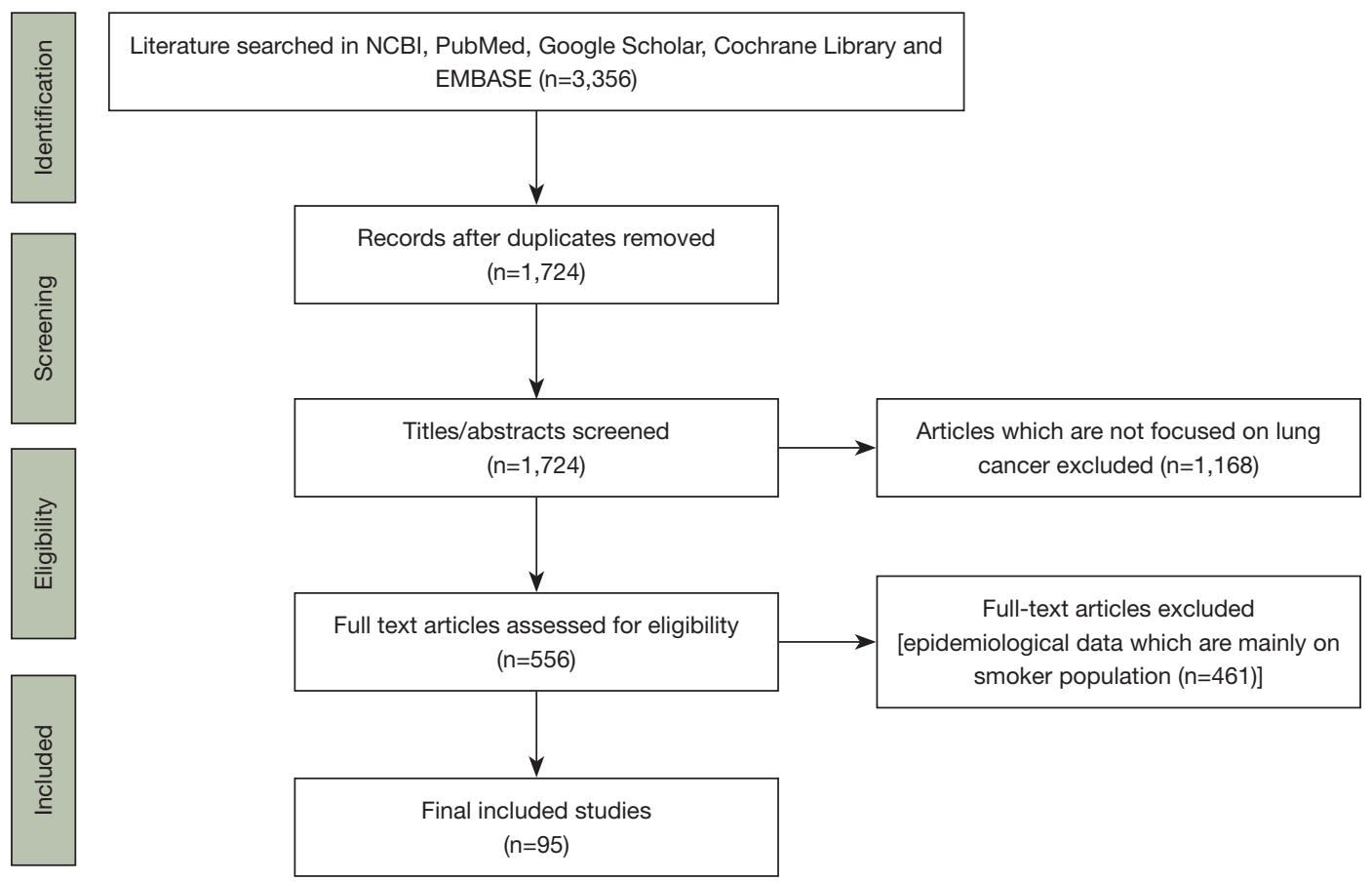

Figure 1 Literature review flow chart. A structured review of the literature (January 2014-February 2021) was performed.

matter $\left(\mathrm{PM}_{10}\right)$, fine $\mathrm{PM}\left(\mathrm{PM}_{2.5}\right), \mathrm{NO}_{2}, \mathrm{SO}_{2}$, and $\mathrm{O}_{3}(13,14)$. $\mathrm{PM}$ is an airborne complex mixture of organic and inorganic particles, in both solid and liquid forms, present in the ambient atmosphere (15). Worldwide ambient $\mathrm{PM}_{2.5}$, was estimated to have contributed to $14.1 \%$ of all lung cancer deaths in 2017 (16). Several studies have reported a strong association between long-term exposure to air pollution and lung cancer in the never-smoker population $(17,18)$.

Although the association between exposure to $\mathrm{PM}$ and lung cancer development is well known, the pathophysiological background is yet to be studied in depth. Furthermore, the incidence and clinical characteristics of PM-related lung cancer differ depending on the region of residence and other epidemiologic factors such as sex $(19,20)$.

Considering the carcinogenic nature of ambient PM and the fact that many patients with lung cancer are never smokers, it is necessary to evaluate the interrelation and possible clinical background, in order to effectively prevent lung cancer development in this subgroup. In this mini-review, the association and pathophysiological link between lung cancer in never smokers and ambient PM are assessed.

We present the following article in accordance with the Narrative Review reporting checklist (available at https:// jtd.amegroups.com/article/view/10.21037/jtd-21-655/rc).

\section{Methods}

\section{Search strategy}

An online search of literature was conducted. The National Center for Biotechnology Information (NCBI), PubMed, Google Scholar, Cochrane Library and EMBASE were searched for articles on association between PM and lung cancer in never smokers (Figure 1). All literature published in English between January 2014 and February 2021 were included. Various combinations of search texts were used. Search word 'particulate matter' and 'lung cancer' was combined with each of the following terms; 'ambient', 'pollution', 'carcinogenesis', 'indoor', 'never smoker', 'mechanism', 'concentration', 'air', 'sex', and 'development'.

\section{Common constituents of PM}

$\mathrm{PM}$ is a dispersed complex mixture of small particles and liquid droplets in air $(21,22)$. It generally enters the human body through inhalation. PM with a relatively larger particle size is blocked in the nasal cavity and upper airway, while fine PM can penetrate deeper into the lower respiratory tract (23). PM is commonly characterized by size fractions into particles with diameter $<10 \mu \mathrm{m}\left(\mathrm{PM}_{10}\right)$ and particles with diameter $<2.5 \mu \mathrm{m}\left(\mathrm{PM}_{2.5}\right) . \mathrm{PM}_{10}$ is the largest inhalable 
particle, while $\mathrm{PM}_{2.5}$, known as fine $\mathrm{PM}$, can be inhaled deep into the lung parenchyma and alveoli (24).

The chemical constituents of PM include nitrates, sulfates, ammonium, other inorganic ions, organic and elemental carbon, crustal material, metals, particle-bound water, and polycyclic aromatic hydrocarbons (PAHs) (25). The constituents of PM can differ depending on the region. In urban areas, incineration of wastes, traffic fumes, mining, and toxic material fuel from the incomplete combustion of biomass or oil fuel comprising metals and metalloids, contribute to $\mathrm{PM}$ (15). A study analyzing $\mathrm{PM}_{2.5}$ components in four Canadian cities showed the presence of mineral dust, trace element oxides, transition metals, ammonium sulfate, black carbon, organic matter, and sea salts (26). These products generate reactive oxygen species (ROS) and activate inflammatory responses, resulting in subsequent genetic mutations in both somatic and germ cells, and altered gene expression, ultimately increasing the risk of cancer (14).

\section{Epidemiologic background of PM as a cause of lung cancer}

\section{Association between ambient PM concentration and lung cancer development}

A study has shown an association between exposure to PM and lung cancer risk in the never-smoker population, which may not be as strong as that in the smoker population (27). Epidemiological evidence showing the association is notable.

Considering that the pollutants causing ambient air pollution are diverse, studies focused on the evaluation of $\mathrm{PM}_{2.5}$ and $\mathrm{PM}_{10}$, which can be detected by air quality monitoring systems. Several large sized-population-based studies have been conducted to evaluate the association between lung cancer risk and PM (28-30). Notable prediction models for the prediction of lung cancer risk in never smokers included the level of $\mathrm{PM}$ as a risk factor (31).

The population data from various countries were evaluated for the severity of air pollution. Studies using nationwide data or large-sized cohorts from the North American population are notable. In a study using the National Health Interview Survey data, in which 341,665 never-smokers were surveyed from 1987 to 2014, an increase of $10 \mu \mathrm{g} / \mathrm{m}^{3}$ in $\mathrm{PM}_{2.5}$ was associated with an increased risk of all-cause mortality $(\mathrm{HR}=1.19$; 95\% CI: 1.06-1.33); an increase in $\mathrm{PM}_{2.5}$ also showed a significant association with lung cancer-related mortality ( $\mathrm{HR}=1.73$;
95\% CI: 1.20-2.49) after adjusting for multiple factors such as age, sex, and ethnicity (30). In another large study using Adventist Health and Smog Study-2 (AHSMOG-2) and US state cancer registries, a $10 \mu \mathrm{g} / \mathrm{m}^{3}$ increment in $\mathrm{PM}_{2.5}$, was significantly associated with incident lung cancer $(\mathrm{HR}=1.43 ; 95 \% \mathrm{CI}: 1.03-2.00)$ after adjusting for sex, educational level, race, $\mathrm{O}_{3}$ level, and smoking status. This result is notable because of the high proportion of never smokers in the cohort (80.8\%) (28).

According to the Nurses' Health Study, $\mathrm{PM}_{2.5}$ (per $10 \mu \mathrm{g} / \mathrm{m}^{3}$ ) showed a significant association with lung cancer incidence after adjusting for age, time period, and geographic region (32). A 26-year prospective study on 188,699 lifelong never-smokers also showed that a $10 \mu \mathrm{g} / \mathrm{m}^{3}$ increase in $\mathrm{PM}_{2.5}$ concentration was associated with a small but measurable increase in lung cancer mortality. In overall patients, each 10 unit-increase in $\mathrm{PM}_{2.5}$ was associated with a $15-27 \%$ increase in lung cancer deaths. This study is important because the heterogeneity in terms of smoking history was more controlled than that in other studies (33).

A plethora of evidence suggests a strong association between increased PM levels and lung cancer incidence; however, even at a relatively low level of $\mathrm{PM}_{2.5}$, lung cancer may occur. In a study evaluating seven cohorts from across Europe, long-term exposure to ambient $\mathrm{PM}_{2.5}$ was associated with lung cancer incidence, and it should be taken into account that the median annual exposure level of $\mathrm{PM}_{2.5}$ was $15.5 \mu \mathrm{g} / \mathrm{m}^{3}$, which is below the $\mathrm{EU}$ limit values. This finding was consistent in the never-smokers subgroup (HR $=1.15$; 95\% CI: 1.01-1.31) (29).

Regarding association between lung cancer risk and $\mathrm{PM}_{10}$, a study on Korean population including 908 lung cancer patient and matching controls showed that lung cancer incidence showed tendencies to increases with a tenunit increase in $\mathrm{PM}_{10}$ (adjusted odds ratio of 1.09 95\% CI: 0.96-1.23), and the associations were stronger among never smokers (34). In another study using the Nurses' Health study, incidence of lung cancer increases with a 10 unit increase in 72-month average $\mathrm{PM}_{10}(\mathrm{HR}=1.04$; 95\% CI: 0.95-1.14). The associations appeared to increase in the never-smokers and former smokers (35). A meta-analyses of 18 studies showed the relationship of exposure to $\mathrm{PM}_{2.5}$ and $\mathrm{PM}_{10}$ with incidence and mortality of lung cancer. The study analyzed lung cancer risk associated with $\mathrm{PM}_{2.5}$ by smoking status. The risk was greatest for former smokers [1.44 (95\% CI: 1.04-1.22)], followed by never-smokers [1.18 (95\% CI: 1.00-1.39)], and then current smokers [1.06 (95\% CI: 0.97-1.15)], showing that the risk is higher for the 
never-smokers than for the current smokers (36).

\section{Biochemical background of interrelationship between PM and lung cancer}

\section{Oxidative stress and inflammation}

$\mathrm{PM}$ induces oxidative stress due to an imbalance in the oxidation and reduction status within the body. Excessive ROS impair cell function and induce cell death $(37,38)$. In order to overcome the adverse effects of PM, the lungs have a unique protective system in which glutathione (GSH) plays an important role in neutralizing oxidative stress (39-41). The lungs are exposed to high concentrations of oxygen; hence, a balance between oxidants and antioxidants is critical. Excessive oxidative stress leads to chronic inflammation in the lung tissue, attracting diverse inflammatory cells, and subsequently DNA damage occurs, which in turn is associated with an increased possibility of lung cancer development $(38,42)$.

Recent studies have reported new aspects of PMrelated oxidative stress in the lung tissue. A study by Niu et al. (43), using human bronchial epithelial (HBE) cells, showed increased levels of ROS, malondialdehyde, and cellular heme oxygenase and decreased levels of GSH, after exposure to $\mathrm{PM}_{2.5}$, reflecting the occurrence of oxidative stress in a dose-dependent manner. Quantitative analysis indicated that $\mathrm{PM}_{2.5}$ caused a significant increase in malondialdehyde in a dose-dependent manner, while GSH was greatly reduced after exposure $(\mathrm{P}<0.05)$. $\mathrm{PM}$-induced oxidative stress induces inflammatory reactions in the lung tissue through various pathways. Liu et al. (44) showed that oxidative stress induced by $\mathrm{PM}_{2.5}$ increases intercellular adhesion molecule-1 expression (ICAM-1), which mediates inflammatory cells in the lung epithelial cells through the IL-6/AKT/STAT3/NF-кB signaling pathway. Wang et al. (45) demonstrated that PM exposure increased the levels of inflammatory cytokines and pro-inflammatory cytokines through ROS-mediated activation of MAPK and downstream NF- $\kappa \mathrm{B}$ pathways. Hu et al. (46) showed that environmental levels of both $\mathrm{PM}_{2.5}$ and total PAHs were significantly correlated with increased PAH metabolite levels in the urine of human subjects, while urinary metal metabolite levels were significantly correlated with oxidative stress biomarkers, suggesting a dose-dependent relationship between exposure to metal components and oxidative stress. In the study, $\mathrm{PM}_{2.5}$ bound PAHs and metals showed significant exposure-response relationship with markers of oxidative stress, and it was illustrated that the levels of urinary metal metabolites such as $8-\mathrm{OHdG}, 8$-iso-PGF2 $\alpha$ and MDA gradually elevated with increasing environmental $\mathrm{PM}_{2.5}$ exposure.

\section{Genotoxicity and malignant transformation}

Damage to DNA, oxidative stress induced or not, is a significant contributing factor to cancer development (47). Accumulation of damaged DNA beyond the host's repair capability leads to irreversible changes, resulting in malignant transformations $(1,48)$.

Air pollutants include several mutagenic carcinogens, such as PAHs (e.g., benzopyrene and polar compounds), sulfur-containing compounds $\left(\mathrm{SO}_{3}, \mathrm{H}_{2} \mathrm{SO}_{4}\right)$, dioxins, and 3-nitrobenzanthrone (49-52). Epigenetic changes in the genome are considered to mediate the effects of air pollutants on lung cancer development (53). Long-term exposure to the chemical constituents of PM ultimately generates genetic mutations and defects in gene expression (14), as proved in animal and in vitro experiments (54-56).

Niu et al. (43) showed that after exposure of $16 \mathrm{HBE}$ to $\mathrm{PM}_{2.5}$, the micronucleus rate was elevated, and various indicator proteins such as $\gamma-\mathrm{H} 2 \mathrm{AX}$ and $8-\mathrm{OH}-\mathrm{dG}$ were remarkably enhanced, indicating subsequent DNA damage. In addition, the changes in the indicator proteins became more evident as the $\mathrm{PM}_{2.5}$ levels increased.

Epithelial mesenchymal transition (EMT), which is involved in cancer progression and metastasis, is reportedly induced by $\mathrm{PM}_{2.5}$, according to several in vitro studies (57). Guo et al. (58) showed that organic components from traffic-originated $\mathrm{PM}_{2.5}$, promoted lung adenocarcinoma cell invasion and migration via the notch 1 signaling pathway. HBE cell lines treated with $\mathrm{PM}_{2.5}$ induced EMT, while involving metastasis-associated lung adenocarcinoma transcript 1 (MALAT1) (59).

PM also affects the behavior of preformed cancer cells. Cancer cells exposed to $\mathrm{PM}_{2.5}$ show active molecular signatures and cellular processes related to their invasive and proliferative properties $(1,60)$. Similarly, Wei et al. (61) using the A549 cell model, showed that $\mathrm{PM}_{2.5}$ exposure increases migration and invasion of cancer cells. Lu et al. (62) using A549 cells, showed that exposure to PM significantly suppresses miR-26a to upregulate lin-28 homolog B (LIN28B), subsequently upregulating interleukin 6 and signal transducer and activator of transcription 3 . This process eventually contributes to EMT, cancer migration, and invasion. In another study using A549 cells and nude 
mice, $\mathrm{Xu}$ et al. (63) showed that exosomes produced after exposure to $\mathrm{PM}_{2.5}$, may promote the growth of lung tumor cells in vitro and in vivo via the $W n t 3 a / \beta$-catenin pathway. Using the acute and chronic exposure model, Wei et al. (61) showed that $\mathrm{PM}_{2.5}$ exposure enhanced cell migration and invasion of A549 cells and further induced EMT and cancer stem cell properties.

PM-related genotoxicity has also been observed in human subjects. In a study including 72 subjects from Taiwan, 8-oxo-7, 8-dihydro-2-deoxyguanosine (8-oxodG) and N7methylguanine (N7MeG), which are biomarkers correlated with oxidative and methylated DNA damage, were longitudinally measured. N7-MeG levels had significantly increased with increasing $\mathrm{PM}_{2.5}$, whereas 8-oxodG levels were positively correlated with $\mathrm{N} 7-\mathrm{MeG}$ levels (64). A study comparing traffic policemen and office policemen showed that increased cumulative intersection duty time was associated with increases in 8-hydroxy-20deoxyguanosine, tail DNA, micronucleus frequency, and a decrease in GSH. These findings support the hypothesis that longer exposure to air pollution can induce cumulative DNA damage (65). Alterations in DNA structure may increase the risk of cancer cell development. Among different mechanisms, epigenetic alterations involving DNA methylation and histone modification are involved in carcinogenesis by PAHs, the major component of PM (66). DNA methylation can prevent transcription of tumor suppressor genes, which can lead to development of cancer cells (67). Histone acetylation via histone acetyltransferases decreases histone protein affinity, facilitating DNA transcription process. Alterations in histone acetylation process may deter DNA transcription, increasing the chance of carcinogenesis (68).

However, until now, there has been no target pathway established, to enable therapeutic management and reduce cancer risk. Future studies that consider the chemical constituents of PM need to be conducted to clarify the pathophysiological mechanisms underlying the carcinogenesis of PM.

\section{Possible genetic biomarkers predicting carcinogenesis}

Evaluation of the association between genetic factors and risk of lung cancer among patients who are exposed to ambient PM is necessary, as we can focus on the group with certain genetic conditions, to prevent the risk of lung cancer more effectively.

In a study including 1,142 individuals from Taiwan, $\mathrm{SOX}_{2}$ promoter methylation was shown to be a potential biomarker for industrial air pollution exposure and reflected a predisposition to cancer (69). Exposure to $\mathrm{PM}_{10}$ was shown to cause lung cancer development and the genetic changes subsequent to $\mathrm{PM}_{10}$ exposure were demonstrated in vitro, by Kang et al. (70). The lung epithelial cells were exposed to $\mathrm{PM}_{10}$ like fine dust, at a concentration of $50 \mu \mathrm{g} / \mathrm{mL}$. After culture, the extracted RNA was subjected to next generation sequencing (NGS) and the genes that showed significant changes were validated by quantitative real-time polymerase chain reaction (qRT-PCR). The four upregulated genes were CYP1A1, CYP1B1, LINC01816, and BPIFA2. The study concluded that development of lung cancer due to $\mathrm{PM}_{10}$ exposure may involve the activation of CYP1A1, CYP1B1, and LINC01816, considering that CYP1A1 and CYP1B1 contribute to the development of lung cancer by metabolizing PCAH. Another study showed that telomere length in peripheral blood leukocytes is associated with lung cancer development and may be affected by exposure to coal smoke. Subjects were enrolled from the same province, and those in the tertile with the shortest telomere lengths had approximate four-fold increased risk of developing lung cancer (71).

\section{Clinical characteristics of PM attributable to lung cancer}

\section{Influence on lung cancer patbologic type}

Regarding the cancer types, several studies have shown a strong association between PM exposure and adenocarcinoma development $(72,73)$. For each $10 \mu \mathrm{g} / \mathrm{m}^{3}$ increase in ambient $\mathrm{PM}_{2.5}$, the risk of adenocarcinoma significantly increased (72). However, other factors such as smoking should be taken into account when discussing the association between ambient $\mathrm{PM}$ and specific pathologic subtypes; certain subtypes such as squamous cell cancer and small cell types are strongly linked to tobacco smoking.

\section{Sex difference}

It has been suggested that female patients with lung cancer have different etiologies and they should be regarded as a distinct entity $(6,74)$. Furthermore, the proportion of smokers among female lung cancer patients is usually much lower than that in male patients, depending on the country of residence $(75,76)$. Several studies, mainly from Asian countries, have shown that women may be more susceptible to air pollution in terms of lung cancer risk (77-79). A study 
in China showed that $\mathrm{PM}_{10}$ is most closely related to lung cancer development, and women are more likely to develop lung cancer from air pollution than men. Data envelopment analysis effectiveness between air pollution and female patients was greater than that of male patients, showing that women are more susceptible to lung cancer caused by air pollution. Furthermore, when different groups of patients were compared, female non-smokers were at higher risk from air pollution induced lung cancer than male nonsmokers (77). Regarding $\mathrm{PM}_{2.5}$, the risk ratio for lung cancer was significantly higher among women than men. The study participants who were women were mainly never smokers compared to $48 \%$ of men who were smokers in the same province. The authors further discussed that this may be due to exposure to indoor cooking oil fumes (78). The difference in lung cancer risk based on sex, was also observed in a study on Korean metropolitan citizens who were exposed to $\mathrm{PM}_{10}$ for a long period, however, smoking status was not adjusted in the analysis (79).

Based on the presumption that ambient air pollution results in a higher risk of lung cancer development among women than men, several factors can be considered to be possible reasons. First, women have a smaller body mass than men. In a study based on nationwide data from Korea, low BMI $\left(<18.5 \mathrm{~kg} / \mathrm{m}^{2}\right)$ was a significant independent risk factor for a higher incidence of lung cancer among neversmoking women (80). Second, women may have additional risk factors associated with the development of lung cancer. In East Asia, women have a propensity to spend time cooking and are more likely to be exposed to increased levels of PM from burning fuels such as coal than men (81-86). It is difficult to separate the respective impacts of ambient air pollution and indoor pollution because the two factors often correlate with each other. However, in order to manage the risk factors more effectively, we believe that separate evaluation of ambient air pollution and indoor air pollution is important, and it can be achieved by utilizing the data of populations that show predominant exposure to either of the two factors.

\section{Indoor air pollution}

Most of the studies on PM have focused on ambient PM owing to the relative availability of level measurements. Indoor $\mathrm{PM}_{2.5}$ consists of elemental carbon components that originate from smoldering combustion in contrast to the elemental carbon components from internal combustion engine exhaust soot, in outdoor $\mathrm{PM}_{2.5}$, (87). Aside from second-hand and third-hand tobacco smoke, which are reported to significantly influence indoor PM levels (88), pollutants from indoor cooking are also a significant source of PM. Many studies have shown an association between indoor cooking and use of coal as a fuel within the house, with an increased risk of lung cancer development (81-86).

Most of the studies on association between indoor cooking and risk of lung cancer were conducted in East Asia, the majority of which were from China (89-92). Cooking oil fumes account for a significant proportion of indoor cooking-related PM (93). A case-control study from Taiwan, which was conducted on 1,302 lung cancer patients and the same number of matched healthy controls, showed a dose-response association between cooking fume exposure and lung cancer incidence. While long-term use of a fume extractor during cooking reduces the risk of lung cancer, cooking habits are also important factors affecting the risk of lung cancer (94). A meta-analysis including 23 observational studies and 9,411 lung cancer cases showed that the pooled odds ratio of cooking oil fume exposure was 1.98 (95\% CI: 1.54-2.54; I $\mathrm{I}^{2}=79 \%$ ) among the non-smoking female population, suggesting that cooking oil fumes are a risk factor for lung cancer in women. Similar to a previous study, poor ventilation and cooking methods such as stir frying, were considered to increase the risk of lung cancer (89). The chemical composition of $\mathrm{PM}_{2.5}$ obtained from cooking oil fumes showed a distinction from $\mathrm{PM}_{2.5}$ from other sources. $\mathrm{PM}_{2.5}$ from cooking oil fumes include benzo(a)pyrene, benzo(a)anthracene, $\mathrm{SO}_{4}{ }^{2-}, \mathrm{NO}^{3-}$, and $\mathrm{NH}_{4}{ }^{+}$, and have higher concentrations of five PAHs than that in $\mathrm{PM}_{2.5}$ derived from other sources such as ambient air or incense burning $(93,95,96)$. Liu et al. (93) further showed that $\mathrm{PM}_{2.5}$ led to cell death, oxidative stress, apoptosis, and cell arrest in primary fetal alveolar cells.

Indoor air pollution, in which indoor cooking plays a major role, may contribute considerably to never-smoking female lung cancer, but epidemiological data supporting this hypothesis are still lacking. In both developing and developed countries, more studies should be conducted to clarify the pathophysiological link between indoor air pollution and the risk of lung cancer.

\section{Cancer prevention and future direction}

Efforts to prevent cancer attributable to PM may include measures such as avoiding outdoor activities when air quality is poor and wearing particle-filtering masks. Regarding indoor air pollution, it is necessary to remove 
possible sources of indoor elemental carbon components through appropriate ventilation. However, a more largescale, organized approach should be implemented. Public and government efforts to improve air quality are essential. Constant monitoring of hazardous airborne PM levels of different particle fractions and strict control over sources, such as incineration of wastes, traffic fumes, and combustion of biomass or oil fuel are necessary. In addition, more research should be conducted to determine how constituents of PM induce carcinogenesis and identify the subjects that have a high risk of developing lung cancer when exposed to PM. When conducting future research, regions where the study population reside should be considered as a major factor because concentrations of air pollutants, climate, racial differences, and cultural backgrounds may affect the impact of PM. For example, indoor air pollution due to indoor cooking, tends to be more severe in developing countries due to a lack of ventilation systems and indoor burning of biomass fuels $(97,98)$. Other factors such as ultrafine PM (PM 0.1), which received relatively less clinical attention, should also be evaluated for pathological backgrounds leading to cancer development (24).

Since oxidative stress induced by PM is the major mechanism of lung cancer development, antioxidant usage could be a potential cancer prevention modality. It has been reported that carotenoids, vitamin $\mathrm{C}$, and vitamin $\mathrm{E}$ have protective effects against lung cancer (99). Antioxidant products may have some benefit in decreasing the risk of lung cancer; however, evidence supporting the routine use of antioxidants among the population at risk is insufficient, and further studies are necessary (1).

\section{Conclusions}

In never smokers, the risk of lung cancer was dosedependent with the concentration of ambient air pollutants. Considering the significant burden of PM on lung cancer development, both public and clinical approaches to cancer prevention are essential. To prevent lung cancer more effectively, clinicians should develop a more individualized approach in patients, focusing on gender and genetic background. The association between exposure to PM and lung cancer development has been well studied, even among never smokers. Regarding the pathophysiological link, involvement of EMT and chronic inflammation has been mentioned, but further studies are necessary to enable therapeutic interventions to prevent cancer development. Other factors that can aggravate the hazardous impact of ambient PM, such as indoor pollution, smoking, and other epidemiological factors, should also be controlled.

\section{Acknowledgments}

We would like to thank Editage (https://www.editage.co.kr) for English language editing.

Funding: None.

\section{Footnote}

Provenance and Peer Review: This article was a standard submission to the journal for the Air Pollution Section. The article has undergone external peer review.

Reporting Checklist: The authors have completed the Narrative Review reporting checklist. Available at https:// jtd.amegroups.com/article/view/10.21037/jtd-21-655/rc

Conflicts of Interest: Both authors have completed the ICMJE uniform disclosure form (available at https://jtd.amegroups. com/article/view/10.21037/jtd-21-655/coif). The authors have no conflicts of interest to declare.

Ethical Statement: The authors are accountable for all aspects of the work in ensuring that questions related to the accuracy or integrity of any part of the work are appropriately investigated and resolved.

Open Access Statement: This is an Open Access article distributed in accordance with the Creative Commons Attribution-NonCommercial-NoDerivs 4.0 International License (CC BY-NC-ND 4.0), which permits the noncommercial replication and distribution of the article with the strict proviso that no changes or edits are made and the original work is properly cited (including links to both the formal publication through the relevant DOI and the license). See: https://creativecommons.org/licenses/by-nc-nd/4.0/.

\section{References}

1. Lee CW, Vo TTT, Wu CZ, et al. The Inducible Role of Ambient Particulate Matter in Cancer Progression via Oxidative Stress-Mediated Reactive Oxygen Species Pathways: A Recent Perception. Cancers (Basel) 2020;12:2505.

2. Prizment AE, Yatsuya H, Lutsey PL, et al. Smoking behavior and lung cancer in a biracial cohort: the 
Atherosclerosis Risk in Communities study. Am J Prev Med 2014;46:624-32.

3. Sun S, Schiller JH, Gazdar AF. Lung cancer in never smokers-a different disease. Nat Rev Cancer 2007;7:778-90.

4. Pallis AG, Syrigos KN. Lung cancer in never smokers: disease characteristics and risk factors. Crit Rev Oncol Hematol 2013;88:494-503.

5. Cao Q, Rui G, Liang Y. Study on PM2.5 pollution and the mortality due to lung cancer in China based on geographic weighted regression model. BMC Public Health 2018;18:925.

6. Park CK, Kim SJ. Trends and Updated Statistics of Lung Cancer in Korea. Tuberc Respir Dis (Seoul) 2019;82:175-7.

7. Park JY, Jang SH. Epidemiology of Lung Cancer in Korea: Recent Trends. Tuberc Respir Dis (Seoul) 2016;79:58-69.

8. Cho J, Choi SM, Lee J, et al. Proportion and clinical features of never-smokers with non-small cell lung cancer. Chin J Cancer 2017;36:20.

9. Zeng Q, Vogtmann E, Jia MM, et al. Tobacco smoking and trends in histological subtypes of female lung cancer at the Cancer Hospital of the Chinese Academy of Medical Sciences over 13 years. Thorac Cancer 2019;10:1717-24.

10. Korea S. Annual prevalence of newly diagnosed lung cancer. Daejeon: Statistics Korea, 2019. Available online: http://kosis.kr/statHtml/statHtmldo?orgId=117\&tblId=D T_117N_A00023\&conn_path=I2

11. Couraud S, Zalcman G, Milleron B, et al. Lung cancer in never smokers-a review. Eur J Cancer 2012;48:1299-311.

12. Shankar A, Dubey A, Saini D, et al. Environmental and occupational determinants of lung cancer. Transl Lung Cancer Res 2019;8:S31-49.

13. Loomis D, Huang W, Chen G. The International Agency for Research on Cancer (IARC) evaluation of the carcinogenicity of outdoor air pollution: focus on China. Chin J Cancer 2014;33:189-96.

14. Loomis D, Grosse Y, Lauby-Secretan B, et al. The carcinogenicity of outdoor air pollution. Lancet Oncol 2013;14:1262-3.

15. WHO. Health effects of particulate matter. Policy implications for countries in eastern Europe, Caucasus and central Asia. Geneva: World Health Organization, 2013.

16. GBD 2017 Risk Factor Collaborators. Global, regional, and national comparative risk assessment of 84 behavioural, environmental and occupational, and metabolic risks or clusters of risks for 195 countries and territories, 19902017: a systematic analysis for the Global Burden of Disease Study 2017. Lancet 2018;392:1923-94. Erratum in: Lancet 2019;393:132; Lancet 2019;393:e44.

17. Guo Y, Zeng H, Zheng R, et al. The association between lung cancer incidence and ambient air pollution in China: A spatiotemporal analysis. Environ Res 2016;144:60-5.

18. Raaschou-Nielsen O, Andersen ZJ, Beelen R, et al. Air pollution and lung cancer incidence in 17 European cohorts: prospective analyses from the European Study of Cohorts for Air Pollution Effects (ESCAPE). Lancet Oncol 2013;14:813-22.

19. Huang F, Pan B, Wu J, et al. Relationship between exposure to PM2.5 and lung cancer incidence and mortality: A meta-analysis. Oncotarget 2017;8:43322-31.

20. Ciabattini M, Rizzello E, Lucaroni F, et al. Systematic review and meta-analysis of recent high-quality studies on exposure to particulate matter and risk of lung cancer. Environ Res 2021;196:110440.

21. Neri T, Pergoli L, Petrini S, et al. Particulate matter induces prothrombotic microparticle shedding by human mononuclear and endothelial cells. Toxicol In Vitro 2016;32:333-8.

22. Wilson WE, Chow JC, Claiborn C, et al. Monitoring of particulate matter outdoors. Chemosphere 2002;49:1009-43.

23. Mo JH. Association of Particulate Matter With ENT Diseases. Clin Exp Otorhinolaryngol 2019;12:237-8.

24. Turner MC, Andersen ZJ, Baccarelli A, et al. Outdoor air pollution and cancer: An overview of the current evidence and public health recommendations. CA Cancer J Clin 2020. [Epub ahead of print]. doi: 10.3322/caac.21632.

25. Hashim D, Boffetta P. Occupational and environmental exposures and cancers in developing countries. Ann Glob Health 2014;80:393-411.

26. Shahpoury P, Zhang ZW, Arangio A, et al. The influence of chemical composition, aerosol acidity, and metal dissolution on the oxidative potential of fine particulate matter and redox potential of the lung lining fluid. Environ Int 2021;148:106343.

27. Tomczak A, Miller AB, Weichenthal SA, et al. Longterm exposure to fine particulate matter air pollution and the risk of lung cancer among participants of the Canadian National Breast Screening Study. Int J Cancer 2016;139:1958-66.

28. Gharibvand L, Shavlik D, Ghamsary M, et al. The Association between Ambient Fine Particulate Air Pollution and Lung Cancer Incidence: Results from the AHSMOG-2 Study. Environ Health Perspect 2017;125:378-84.

29. Hvidtfeldt UA, Severi G, Andersen ZJ, et al. Long-term 
low-level ambient air pollution exposure and risk of lung cancer - A pooled analysis of 7 European cohorts. Environ Int 2021;146:106249.

30. Coleman NC, Burnett RT, Higbee JD, et al. Cancer mortality risk, fine particulate air pollution, and smoking in a large, representative cohort of US adults. Cancer Causes Control 2020;31:767-76.

31. Warkentin MT, Lam S, Hung RJ. Determinants of impaired lung function and lung cancer prediction among never-smokers in the UK Biobank cohort. EbioMedicine 2019;47:58-64.

32. Chang ET, Lau EC, Moolgavkar SH. Smoking, air pollution, and lung cancer risk in the Nurses' Health Study cohort: time-dependent confounding and effect modification. Crit Rev Toxicol 2020;50:189-200.

33. Turner MC, Krewski D, Pope CA 3rd, et al. Long-term ambient fine particulate matter air pollution and lung cancer in a large cohort of never-smokers. Am J Respir Crit Care Med 2011;184:1374-81.

34. Lamichhane DK, Kim HC, Choi CM, et al. Lung Cancer Risk and Residential Exposure to Air Pollution: A Korean Population-Based Case-Control Study. Yonsei Med J 2017;58:1111-8.

35. Puett RC, Hart JE, Yanosky JD, et al. Particulate matter air pollution exposure, distance to road, and incident lung cancer in the nurses' health study cohort. Environ Health Perspect 2014;122:926-32.

36. Hamra GB, Guha N, Cohen A, et al. Outdoor particulate matter exposure and lung cancer: a systematic review and meta-analysis. Environ Health Perspect 2014;122:906-11.

37. Garçon G, Dagher Z, Zerimech F, et al. Dunkerque City air pollution particulate matter-induced cytotoxicity, oxidative stress and inflammation in human epithelial lung cells (L132) in culture. Toxicol In Vitro 2006;20:519-28.

38. Kim HJ, Choi MG, Park MK, et al. Predictive and Prognostic Biomarkers of Respiratory Diseases due to Particulate Matter Exposure. J Cancer Prev 2017;22:6-15.

39. Boyd MR, Stiko A, Statham CN, et al. Protective role of endogenous pulmonary glutathione and other sulfhydryl compounds against lung damage by alkylating agents. Investigations with 4-ipomeanol in the rat. Biochem Pharmacol 1982;31:1579-83.

40. Meister A. New aspects of glutathione biochemistry and transport: selective alteration of glutathione metabolism. Fed Proc 1984;43:3031-42.

41. Dalton TP, Chen Y, Schneider SN, et al. Genetically altered mice to evaluate glutathione homeostasis in health and disease. Free Radic Biol Med 2004;37:1511-26.
42. Reuter S, Gupta SC, Chaturvedi MM, et al. Oxidative stress, inflammation, and cancer: how are they linked? Free Radic Biol Med 2010;49:1603-16.

43. Niu BY, Li WK, Li JS, et al. Effects of DNA Damage and Oxidative Stress in Human Bronchial Epithelial Cells Exposed to PM2.5 from Beijing, China, in Winter. Int J Environ Res Public Health 2020;17:4874.

44. Liu CW, Lee TL, Chen YC, et al. PM2.5-induced oxidative stress increases intercellular adhesion molecule-1 expression in lung epithelial cells through the IL-6/AKT/ STAT3/NF- $\kappa$ B-dependent pathway. Part Fibre Toxicol 2018;15:4.

45. Wang J, Huang J, Wang L, et al. Urban particulate matter triggers lung inflammation via the ROS-MAPK-NF- $\kappa \mathrm{B}$ signaling pathway. J Thorac Dis 2017;9:4398-412.

46. $\mathrm{Hu} W$, Wang $\mathrm{Y}$, Wang $\mathrm{T}$, et al. Ambient particulate matter compositions and increased oxidative stress: Exposureresponse analysis among high-level exposed population. Environ Int 2021;147:106341.

47. Kastan MB. DNA damage responses: mechanisms and roles in human disease: 2007 G.H.A. Clowes Memorial Award Lecture. Mol Cancer Res 2008;6:517-24.

48. Yang L, Liu G, Fu L, et al. DNA repair enzyme OGG1 promotes alveolar progenitor cell renewal and relieves PM2.5-induced lung injury and fibrosis. Ecotoxicol Environ Saf 2020;205:111283.

49. Arlt VM. 3-Nitrobenzanthrone, a potential human cancer hazard in diesel exhaust and urban air pollution: a review of the evidence. Mutagenesis 2005;20:399-410.

50. Castaño-Vinyals G, D'Errico A, Malats N, et al. Biomarkers of exposure to polycyclic aromatic hydrocarbons from environmental air pollution. Occup Environ Med 2004;61:e12.

51. Manisalidis I, Stavropoulou E, Stavropoulos A, et al. Environmental and Health Impacts of Air Pollution: A Review. Front Public Health 2020;8:14.

52. Yamagishi K, Onuma K, Chiba Y, et al. Generation of gaseous sulfur-containing compounds in tumour tissue and suppression of gas diffusion as an antitumour treatment. Gut 2012;61:554-61.

53. Straif K, Cohen A, Samet J. IARC Scientific Publication no. 161: Air Pollution and Cancer. Lyon: International Agency for Research on Cancer, 2013.

54. Bhetraratana M, Orozco LD, Hong J, et al. Diesel exhaust particles dysregulate multiple immunological pathways in murine macrophages: Lessons from microarray and scRNA-seq technologies. Arch Biochem Biophys 2019;678:108116. 
55. Kim HS, Kim BG, Park S, et al. Gene Expression Analysis to Investigate Biological Networks Underlying Nasal Inflammatory Dysfunctions Induced by Diesel Exhaust Particles Using an In Vivo System. Ann Otol Rhinol Laryngol 2020;129:245-55.

56. Zhu J, Zhao Y, Gao Y, et al. Effects of Different Components of PM2.5 on the Expression Levels of NF$\kappa B$ Family Gene mRNA and Inflammatory Molecules in Human Macrophage. Int J Environ Res Public Health 2019;16:1408.

57. Cochard M, Ledoux F, Landkocz Y. Atmospheric fine particulate matter and epithelial mesenchymal transition in pulmonary cells: state of the art and critical review of the in vitro studies. J Toxicol Environ Health B Crit Rev 2020;23:293-318.

58. Guo H, Feng Y, Yu H, et al. A novel lncRNA, loc107985872, promotes lung adenocarcinoma progression via the notch1 signaling pathway with exposure to traffic-originated PM2.5 organic extract. Environ Pollut 2020;266:115307.

59. Luo F, Wei H, Guo H, et al. LncRNA MALAT1, an lncRNA acting via the miR-204/ZEB1 pathway, mediates the EMT induced by organic extract of PM2.5 in lung bronchial epithelial cells. Am J Physiol Lung Cell Mol Physiol 2019;317:L87-98.

60. Yang B, Chen D, Zhao H, et al. The effects for PM2.5 exposure on non-small-cell lung cancer induced motility and proliferation. Springerplus 2016;5:2059.

61. Wei H, Liang F, Cheng W, et al. The mechanisms for lung cancer risk of PM2.5 : Induction of epithelialmesenchymal transition and cancer stem cell properties in human non-small cell lung cancer cells. Environ Toxicol 2017;32:2341-51.

62. Lu YY, Lin Y, Ding DX, et al. MiR-26a functions as a tumor suppressor in ambient particulate matter-bound metal-triggered lung cancer cell metastasis by targeting LIN28B-IL6-STAT3 axis. Arch Toxicol 2018;92:1023-35.

63. Xu H, Jiao X, Wu Y, et al. Exosomes derived from PM2.5-treated lung cancer cells promote the growth of lung cancer via the $W n t 3 a / \beta$-catenin pathway. Oncol Rep 2019;41:1180-8.

64. Lai CH, Huang HB, Chang YC, et al. Exposure to fine particulate matter causes oxidative and methylated DNA damage in young adults: A longitudinal study. Sci Total Environ 2017;598:289-96.

65. Tan C, Lu S, Wang Y, et al. Long-term exposure to high air pollution induces cumulative DNA damages in traffic policemen. Sci Total Environ 2017;593-594:330-6.
66. Stading R, Gastelum G, Chu C, et al. Molecular mechanisms of pulmonary carcinogenesis by polycyclic aromatic hydrocarbons (PAHs): Implications for human lung cancer. Semin Cancer Biol 2021;76:3-16.

67. Iqbal MA, Arora S, Prakasam G, et al. MicroRNA in lung cancer: role, mechanisms, pathways and therapeutic relevance. Mol Aspects Med 2019;70:3-20.

68. Li J, Li WX, Bai C, et al. Particulate matter-induced epigenetic changes and lung cancer. Clin Respir J 2017;11:539-46.

69. Tantoh DM, Wu MF, Ho CC, et al. SOX2 promoter hypermethylation in non-smoking Taiwanese adults residing in air pollution areas. Clin Epigenetics 2019;11:46.

70. Kang D, Jung IB, Lee SY, et al. Particulate matter less than $10 \mu \mathrm{m}$ (PM10) activates cancer related genes in lung epithelial cells. Inhal Toxicol 2020;32:487-93.

71. Xue Y, Guo X, Huang X, et al. Shortened telomere length in peripheral blood leukocytes of patients with lung cancer, chronic obstructive pulmonary disease in a high indoor air pollution region in China. Mutat Res Genet Toxicol Environ Mutagen 2020;858-860:503250.

72. Gharibvand L, Lawrence Beeson W, Shavlik D, et al. The association between ambient fine particulate matter and incident adenocarcinoma subtype of lung cancer. Environ Health 2017;16:71.

73. Moon DH, Kwon SO, Kim SY, et al. Air Pollution and Incidence of Lung Cancer by Histological Type in Korean Adults: A Korean National Health Insurance Service Health Examinee Cohort Study. Int J Environ Res Public Health 2020;17:915.

74. Domagala-Kulawik J, Trojnar A. Lung cancer in women in 21th century. J Thorac Dis 2020;12:4398-410.

75. Lim JU, Han S, Kim HC, et al. Characteristics of female lung cancer in Korea: analysis of Korean National Lung Cancer Registry. J Thorac Dis 2020;12:4612-22.

76. Ryu JS, Jeon SH, Kim JS, et al. Gender differences in susceptibility to smoking among patients with lung cancer. Korean J Intern Med 2011;26:427-31.

77. Zhou Y, Li L, Hu L. Correlation Analysis of PM10 and the Incidence of Lung Cancer in Nanchang, China. Int J Environ Res Public Health 2017;14:1253.

78. He Y, Gao Z, Guo T, et al. Fine particulate matter associated mortality burden of lung cancer in Hebei Province, China. Thorac Cancer 2018;9:820-6.

79. Hwang SS, Lee JH, Jung GW, et al. Spatial analysis of air pollution and lung cancer incidence and mortality in 7 metropolitan cities in Korea. J Prev Med Public Health 2007;40:233-8. 
80. Ko YH, Kim SJ, Kim WS, et al. Risk factors for primary lung cancer among never-smoking women in South Korea: a retrospective nationwide population-based cohort study. Korean J Intern Med 2020;35:692-702.

81. Thomson P, Robinson K, Robbe IJ. Lung cancer and indoor air pollution arising from Chinese-style cooking among nonsmoking women living in Shanghai, China. Epidemiology 2000;11:481-2.

82. Behera D, Balamugesh T. Indoor air pollution as a risk factor for lung cancer in women. J Assoc Physicians India 2005;53:190-2.

83. Mu L, Liu L, Niu R, et al. Indoor air pollution and risk of lung cancer among Chinese female non-smokers. Cancer Causes Control 2013;24:439-50.

84. Wang TW, Vermeulen RC, Hu W, et al. Gene-expression profiling of buccal epithelium among non-smoking women exposed to household air pollution from smoky coal. Carcinogenesis 2015;36:1494-501.

85. Liu L, Liu X, Ma X, et al. Analysis of the associations of indoor air pollution and tobacco use with morbidity of lung cancer in Xuanwei, China. Sci Total Environ 2020;717:135232.

86. Kim C, Gao YT, Xiang YB, et al. Home kitchen ventilation, cooking fuels, and lung cancer risk in a prospective cohort of never smoking women in Shanghai, China. Int J Cancer 2015;136:632-8.

87. Habre R, Coull B, Moshier E, et al. Sources of indoor air pollution in New York City residences of asthmatic children. J Expo Sci Environ Epidemiol 2014;24:269-78.

88. Ni Y, Shi G, Qu J. Indoor PM2.5, tobacco smoking and chronic lung diseases: A narrative review. Environ Res 2020;181:108910.

89. Jia PL, Zhang C, Yu JJ, et al. The risk of lung cancer among cooking adults: a meta-analysis of 23 observational studies. J Cancer Res Clin Oncol 2018;144:229-40.

Cite this article as: Lim JU, Yoon HK. Narrative review: association between lung cancer development and ambient particulate matter in never-smokers. J Thorac Dis 2022;14(2):553563. doi: $10.21037 /$ jtd-21-655
90. Kim C, Chapman RS, Hu W, et al. Smoky coal, tobacco smoking, and lung cancer risk in Xuanwei, China. Lung Cancer 2014;84:31-5.

91. Lan Q, Chapman RS, Schreinemachers DM, et al. Household stove improvement and risk of lung cancer in Xuanwei, China. J Natl Cancer Inst 2002;94:826-35.

92. Zhou BS, Wang TJ, Guan P, et al. Indoor air pollution and pulmonary adenocarcinoma among females: a case-control study in Shenyang, China. Oncol Rep 2000;7:1253-9.

93. Liu Y, Chen YY, Cao JY, et al. Oxidative stress, apoptosis, and cell cycle arrest are induced in primary fetal alveolar type II epithelial cells exposed to fine particulate matter from cooking oil fumes. Environ Sci Pollut Res Int 2015;22:9728-41.

94. Chen TY, Fang YH, Chen HL, et al. Impact of cooking oil fume exposure and fume extractor use on lung cancer risk in non-smoking Han Chinese women. Sci Rep 2020;10:6774.

95. Chuang HC, Jones T, Chen Y, et al. Characterisation of airborne particles and associated organic components produced from incense burning. Anal Bioanal Chem 2011;401:3095-102.

96. Mansha M, Ghauri B, Rahman S, et al. Characterization and source apportionment of ambient air particulate matter (PM2.5) in Karachi. Sci Total Environ 2012;425:176-83.

97. Ghimire S, Mishra SR, Sharma A, et al. Geographic and socio-economic variation in markers of indoor air pollution in Nepal: evidence from nationally-representative data. BMC Public Health 2019;19:195.

98. Balmes JR. Household air pollution from domestic combustion of solid fuels and health. J Allergy Clin Immunol 2019;143:1979-87.

99. Flagg EW, Coates RJ, Greenberg RS. Epidemiologic studies of antioxidants and cancer in humans. J Am Coll Nutr 1995;14:419-27. 